\title{
Demands in Refrigeration Capacity for the Large Hadron Collider
}

\author{
Ph. Lebrun, G. Riddone, L. Tavian and U. Wagner
}

\begin{abstract}
The capacity demands on the cryogenic installations for the Large Hadron Collider (LHC) at CERN have been recently updated [1]. Unlike the LEP energy upgrade using superconducting acceleration cavities LHC will require high power refrigeration at $1.9 \mathrm{~K}$, as well as non-isothermal cooling at $4.5 \mathrm{~K}$ to $20 \mathrm{~K}$ and at 50 $\mathrm{K}$ to $75 \mathrm{~K}$. This paper presents the assessment of cryogenic capacity that has to be supplied by the eight refrigerators for LHC in relation with the foreseen operating modes of the machine.
\end{abstract}

LHC Division, CERN, CH-1211 Geneva 23, Switzerland

ICEC 16/ICMC, Kitakyushu, Japan, 20-24 May 1996

Administrative Secretariat

LHC Division

CERN

CH - 1211 Geneva 23

Switzerland

Geneva, 11 July 1996 
Demands in Refrigeration Capacity for the Large Hadron Collider

Ph. Lebrun, G. Riddone, L. Tavian and U. Wagner

LHC Division, CERN, CH-1211 Geneva 23, Switzerland

The capacity demands on the cryogenic installations for the Large Hadron Collider (LHC) at CERN have been recently updated [2]. Unlike the LEP energy upgrade using superconducting acceleration cavities LHC will require high power refrigeration at $1.9 \mathrm{~K}$, as well as non-isothermal cooling at $4.5 \mathrm{~K}$ to $20 \mathrm{~K}$ and at 50 $\mathrm{K}$ to $75 \mathrm{~K}$. This paper presents the assessment of cryogenic capacity that has to be supplied by the eight refrigerators for LHC in relation with the foreseen operating modes of the machine.

\section{INTRODUCTION}

Based on today's knowledge the LHC collider will demand a total about 6.6 MW exergetic capacity. Half of this total capacity is to be supplied at $1.8 \mathrm{~K}$ for cooling the cold mass of the superconducting magnets. The rest is distributed mainly for non isothermal loads at $4.5 \mathrm{~K}$ to $20 \mathrm{~K}$ and $50 \mathrm{~K}$ to $75 \mathrm{~K}$ as well as for the cooling of current leads. Due to the exergetic losses which result from refrigeration at $1.8 \mathrm{~K}$, the eight cryogenic plants will have a total equivalent capacity of $150 \mathrm{~kW}$ at $4.5 \mathrm{~K}$.

The reference design for the current leads is based on the use of high temperature superconductor (HTS) material leaving open the choice of cooling methods [3]. The precise assessment of the heat loads is an important task during the planning phase of the project and has to be kept under tight control.

\section{TEMPERATURE LEVELS}

The staging of temperature levels envisaged for the LHC cryogenic system are:

- thermal shielding between $50 \mathrm{~K}$ and $75 \mathrm{~K}$ as a first major heat intercept, sheltering the cold mass from the bulk of heat inleaks from ambient;

- non-isothermal cooling of the beam screens between $4.5 \mathrm{~K}$ and $20 \mathrm{~K}$ which will shield the cold mass from synchrotron radiation and image currents produced by the high-energy, high-intensity hadron beams;

- quasi-isothermal superfluid helium cooling the magnet cold mass at a maximum temperature of $1.9 \mathrm{~K}$;

- isothermal helium cooling special superconducting magnets in insertion regions, superconducting acceleration cavities, and the lower sections of HTS current leads at a saturation temperature between $4.5 \mathrm{~K}$ and $4.7 \mathrm{~K}$;

- gaseous helium cooling the resistive upper sections of HTS current leads, in forced flow between $20 \mathrm{~K}$ and ambient.

\section{STATIC AND DYNAMIC LOADS}

The term "static loads" is used for all heat loads which are not dependent on the machine operation. This comprises the heat inleaks due to conduction and radiation to the low temperature part inside the cryostats plus the thermal load by pure conduction in all feedthroughs.

The term "dynamic loads" is used for all heat loads which are dependent on the machine operation. This includes loads induced either by the excitation current of the superconducting magnets i.e. in current leads or residual resistive areas of coil splices, or by the circulating particle beams i.e. synchrotron radiation, resistive heating due to image currents or geometrical singularities in the beam channels and 
particle losses. These loads depend strongly on the energy and intensity of the circulating beams and are estimated for the nominal and ultimate operating conditions defined below.

\section{MODES OF OPERATION}

The modes of interest for the cryogenic system are:

- "nominal operation" at $7 \mathrm{TeV}$ beam energy, 2 x $0.536 \mathrm{~A}$ beam current and $1 \times 10^{34} \mathrm{~cm}^{-2} \mathrm{~s}^{-1}$ luminosity;

- "ultimate operation" at $7 \mathrm{TeV}$ beam energy, 2 x $0.848 \mathrm{~A}$ beam current and $2.5 \times 10^{34} \mathrm{~cm}^{-2} \mathrm{~s}^{-1}$ luminosity;

- "low beam intensity operation", still with full beam energy and thus full excitation current in the magnets but negligible beam current;

- "injection standby", characterised by negligible resistive dissipation and beam-induced heat loads in the magnets.

\section{THE ARCS}

The eight arcs, which form the regular part of the LHC will be composed of 46 half-cells, each consisting of three main dipoles, one main quadrupole plus a number of correction magnets [1]. The expected static loads of the main elements in the half cells has been assessed with good confidence and experimentally verified through several independent, yet converging approaches [4-7].

Parallel to the magnet cryostats in the arc runs the cryogenic distribution line from which each halfcell is supplied with cryogenic fluids. The heat loads of this line are estimated based on conceptual design drawings and will have to be validated in future prototype tests. Table 1 shows the total heat load budgeted for an LHC arc in the four machine operation modes described above.

Table 1 Total heat load for an LHC arc (no contingency included)

\begin{tabular}{lcccc}
\hline Operating mode & \multicolumn{3}{c}{ Temperature levels } & Comments \\
& $50-75 \mathrm{~K}$ & $4.5-20 \mathrm{~K}$ & $1.9 \mathrm{~K}$ & \\
& {$[\mathrm{~W}]$} & {$[\mathrm{W}]$} & {$[\mathrm{W}]$} & static \& dynamic nominal \\
Nominal operation & 15800 & 1930 & 1070 & static \& dynamic ultimate \\
Ultimate operation & 15800 & 3630 & 1040 & static \& magnet current induced \\
Low-beam-intensity & 15800 & 310 & 920 & pure static load \\
Injection standby & 15700 & 310 & 660 &
\end{tabular}

\section{THE INSERTIONS}

The insertions consist of $0.5 \mathrm{~km}$ long sections connecting the arcs. They include dispersion suppressor, beam separation and recombination, RF acceleration and beam focusing sections on each side of the collision points. Each cryogenic sector includes two half insertions at the both ends of an arc. Since the detailed design of the superconducting magnets in the insertions has not yet been finalised, their expected heat loads have been assessed by approximate scaling from the better defined arc magnets. The results, displayed in Table 2, reflect the variations in geometry, layout, functions and operating modes of the different LHC insertions. They also include specific components - for example, superconducting acceleration cavities, which require significant amounts of cryogenic refrigeration as well as reference magnets for field tracking measurements. Also appearing in these tables are the localised heat loads in the current leads of the different excitation circuits, and based on the use of high-temperature superconductors.

Special heat loads have to be accounted for all elements close to the high luminosity physics experiments due to absorption of secondary particles in the cold mass of the superconducting magnets located close to the experimental areas. The values for the whole machine are:

- at the $1.9 \mathrm{~K} \mathrm{level,} \mathrm{from} 500 \mathrm{~W}$ (nominal) to $1250 \mathrm{~W}$ (ultimate) in the inner triplets of low-beta quadrupoles, as well as from $54 \mathrm{~W}$ (nominal) to $134 \mathrm{~W}$ (ultimate) in the dispersion suppressor 
- at the $4.7 \mathrm{~K}$ level, from $240 \mathrm{~W}$ (nominal) to $600 \mathrm{~W}$ (ultimate) in the beam separation and recombination dipoles.

Table 2 Total heat loads for the half insertions of the LHC machine at nominal operating conditions (no contingencyincluded)

\begin{tabular}{|c|c|c|c|c|c|}
\hline \multirow[t]{2}{*}{ Half Insertion } & \multicolumn{4}{|c|}{ Temperature Levels } & \multirow{2}{*}{$\begin{array}{c}\text { Gas helium } \\
\text { consumption } \\
20-300 \mathrm{~K} \\
{[\mathrm{~g} / \mathrm{s}]}\end{array}$} \\
\hline & $\begin{array}{c}50-75 \mathrm{~K} \\
{[\mathrm{~W}]}\end{array}$ & $\begin{array}{c}4.5-20 \mathrm{~K} \\
{[\mathrm{~W}]}\end{array}$ & $\begin{array}{c}4.7 \mathrm{~K} \\
{[\mathrm{~W}]}\end{array}$ & $\begin{array}{c}1.9 \mathrm{~K} \\
{[\mathrm{~W}]}\end{array}$ & \\
\hline High-luminosity insertion & 1300 & 125 & 100 & 300 & 11 \\
\hline Low-luminosity insertion & 1350 & 130 & 50 & 150 & 13 \\
\hline Beam-cleaninginsertion & 800 & 120 & 5 & 80 & 2 \\
\hline RF insertion & 1250 & 130 & 380 & 100 & 13 \\
\hline Beam-dump insertion & 1150 & 120 & 5 & 120 & 12 \\
\hline
\end{tabular}

\section{DEMANDS ON THE SECTOR CRYOPLANTS}

The LHC sectors stretch over $3.3 \mathrm{~km}$ between the insertion points. The cryogenic load for each sector comprises those a full arc and two half insertions at each end. A special load to be added for each sector is that resulting from a continuous loss of particles escaping the collimation sections, which may result in a locally deposited heat load estimated at $55 \mathrm{~W}$ (nominal) and $92 \mathrm{~W}$ (ultimate), over a length of a few tens of metres corresponding to the region of aperture restriction.

The total installed cryogenic power to cope with the expected loads for the sectors is determined using a contingency calculation to include for uncertainties and overcapacity. For the heat loads at the 50 $75 \mathrm{~K}$ and the 20 to $300 \mathrm{~K}$ level:

Qinstalled $=\operatorname{Max}\left[\mathrm{Fov}^{*}\right.$ Qnominal; Qultimate $]$

for the heat loads at the $4.5-20 \mathrm{~K}, 4.7 \mathrm{~K}$ and $1.9 \mathrm{~K}$ level:

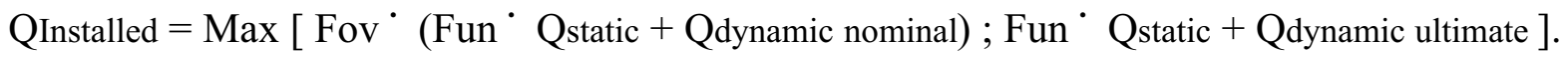

As factor for overcapacity, Fov, 1.5 is used, for uncertainty, Fun, 1.25. Table 3 shows the installed cryogenic power which results for the two types of sectors of the machine. About $250 \mathrm{~W}$ of the load at $1.9 \mathrm{~K}$ listed in Table 3 result from superheating the helium vapour in the $3.3 \mathrm{~km}$ long cryogenic distribution line and do not contribute to the cold compressor flow.

Table 3 Installed cryogenic power requirements of the LHC

\begin{tabular}{|c|c|c|c|c|c|}
\hline \multirow[t]{2}{*}{ Sector } & \multicolumn{4}{|c|}{ Temperature Levels } & \multirow{2}{*}{$\begin{array}{c}\text { Gas helium } \\
\text { consumption } \\
20-300 \mathrm{~K} \\
{[\mathrm{~g} / \mathrm{s}]}\end{array}$} \\
\hline & $\begin{array}{c}50-75 \mathrm{~K} \\
{[\mathrm{~kW}]}\end{array}$ & $\begin{array}{c}4.5-20 \mathrm{~K} \\
{[\mathrm{~kW}]}\end{array}$ & $\begin{array}{l}4.7 \mathrm{~K} \\
{[\mathrm{~kW}]} \\
\end{array}$ & $\begin{array}{l}1.9 \mathrm{~K} \\
{[\mathrm{~kW}]} \\
\end{array}$ & \\
\hline High-load sector & 31.0 & 4.30 & 0.80 & 2.80 & 35 \\
\hline Low-load sector & 30.0 & 4.30 & 0.65 & 2.45 & 23 \\
\hline
\end{tabular}

\section{DAILY LOAD VARIATIONS}

The operation phases which the machine will undergo during a 24 hour period will be four hours of injection standby, during which the storage ring will be adjusted and filled with particles, half an hour of current ramping to reach the operating energy, 19 hours of operation at nominal or eventually ultimate conditions, half an hour of current ramp down to prepare for the new injection. Current ramping will 
Figure 1 shows the development of the load on the $1.9 \mathrm{~K}$ level during the injection and ramp phase leading from the "injection stand-by" to the "nominal" operation mode. Although the rapid changes will be partially buffered by the heat capacity of the pressurised helium II bath, the variations in demand require load adaptation of the cryogenic system over a large dynamic range.

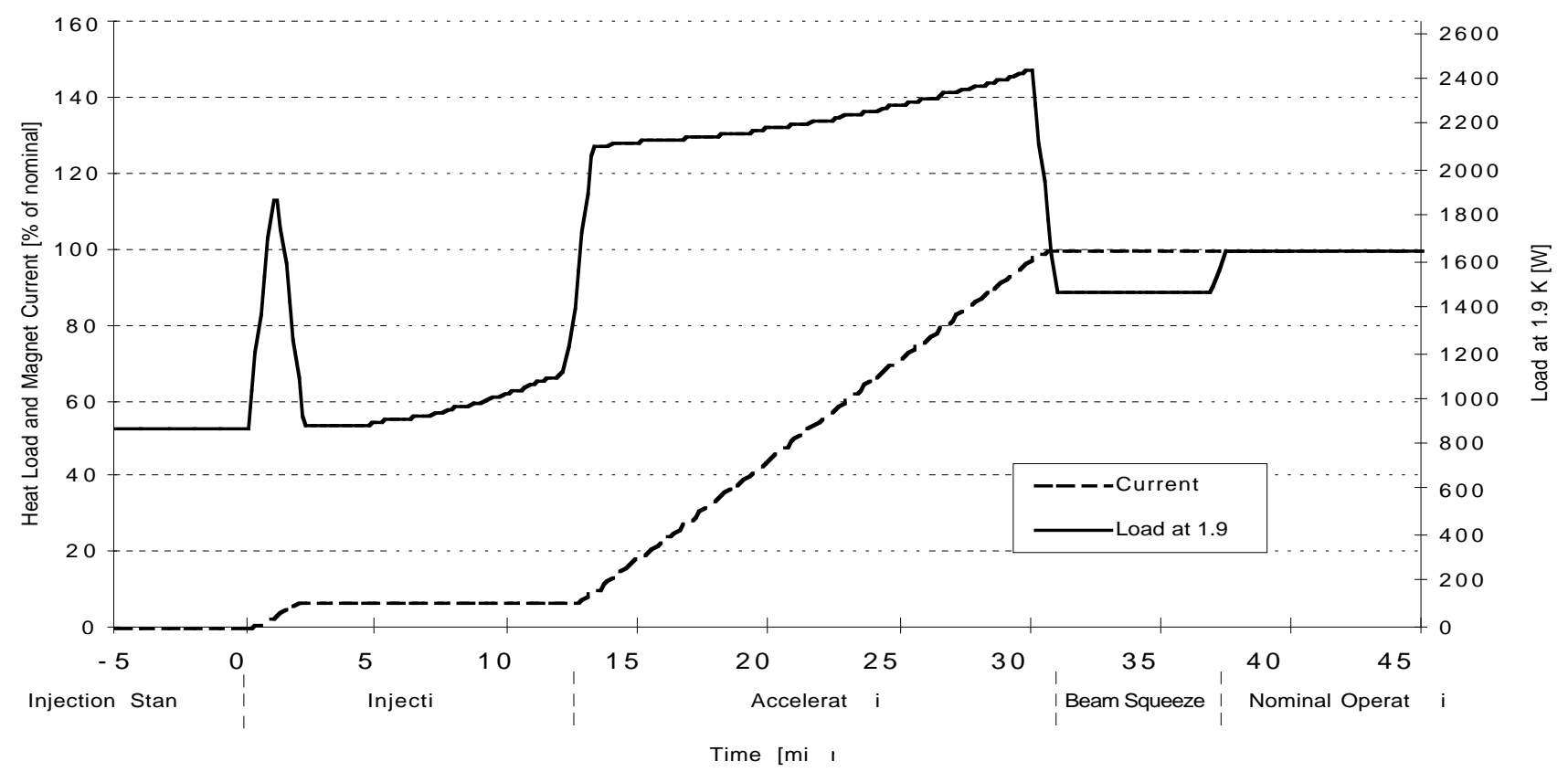

Figure 1 Development of the $1.9 \mathrm{~K}$ load of a high luminosity sector from "injection standby" over magnet ramping to "nominal" capacity operation (no contingency)

\section{CONCLUSIONS}

The demands of refrigeration capacity for the LHC machine have been assessed with increasing accuracy during the recent years. As the project definition is finalised further updates of the heat loads will be necessary. Special attention has to be given to all components which at the moment are still uncertain in their performance like the insertion magnets or assessed by theoretical calculations like the HTS current leads.

\section{REFERENCES}

1 The LHC study group, The Large Hadron Collider, Conceptual Design CERN/AC/95-05(LHC)

2 The LHC study group, The Large Hadron Collider, Conceptual Design CERN/AC/95-05(LHC)

3 Ballarino, A., Ijspeert, A. and Wagner, U., Potential of high-temperature superconducter current leads for LHC cryogenics, paper presented in this conference

4 Jenny, B., Cameron, W., Riddone, G., Rohmig P. and van Weelderen, R., Design and construction of a prototype superfluid helium cryostat for the short straight sections of the CERN Large Hadron Collider, Adv. Cryo. Eng. (1994) 39A 663-670

5 Benda, V., Dufay, L., Ferlin, G., Lebrun, Ph., Rieubland, J.M., Riddone, G., Szeless, B., Tavian L. and Williams, L.R., Measurement and analysis of thermal performance of LHC prototype dipole cryostats paper presented at CEC'95 Columbus (1995)

6 Bézaguet, A., Casas-Cubillos, J., Flemsaeter, B., Gaillard-Grenadier, B., Goiffon, Th., Guinaudeau, H., Lebrun, Ph., Marquet, M., Serio, L., Suraci, A., Tavian L. and van Weelderen, R., The superfluid helium cryogenic system for the LHC Test String: design, construction and first operation paper presented at CEC'95 Columbus (1995)

7 Dufay, L., Ferlin, G., Lebrun, Ph., Riddone, G., Rieubland, J.M., Rijllart, A., Szeless B. and Williams, L.R., A full-scale thermal model of a prototype dipole cryomagnet for the CERN LHC project $\underline{\text { Cryogenics }} 34$ ICEC Supplement, (1994),. 693-696 